\title{
Cellular fluorescein hyperfluorescence is dynamin- dependent and increased by Tetronic 1107 treatment
}

DOI:

10.1016/j.biocel.2018.05.011

\section{Document Version}

Accepted author manuscript

Link to publication record in Manchester Research Explorer

\section{Citation for published version (APA):}

Khan, T., Price, B., Morgan, P., Maldonado-Codina, C., \& Dobson, C. (2018). Cellular fluorescein hyperfluorescence is dynamin-dependent and increased by Tetronic 1107 treatment. The international journal of biochemistry \& cell biology, 101, 54-63. https://doi.org/10.1016/j.biocel.2018.05.011

\section{Published in:}

The international journal of biochemistry \& cell biology

\section{Citing this paper}

Please note that where the full-text provided on Manchester Research Explorer is the Author Accepted Manuscript or Proof version this may differ from the final Published version. If citing, it is advised that you check and use the publisher's definitive version.

\section{General rights}

Copyright and moral rights for the publications made accessible in the Research Explorer are retained by the authors and/or other copyright owners and it is a condition of accessing publications that users recognise and abide by the legal requirements associated with these rights.

\section{Takedown policy}

If you believe that this document breaches copyright please refer to the University of Manchester's Takedown Procedures [http://man.ac.uk/04Y6Bo] or contact uml.scholarlycommunications@manchester.ac.uk providing relevant details, so we can investigate your claim.

\section{OPEN ACCESS}




\section{Accepted Manuscript}

Title: Cellular fluorescein hyperfluorescence is

dynamin-dependent and increased by Tetronic 1107 treatment

Authors: Tahmina F. Khan, Bianca L. Price, Philip B. Morgan, Carole Maldonado-Codina, Curtis B. Dobson

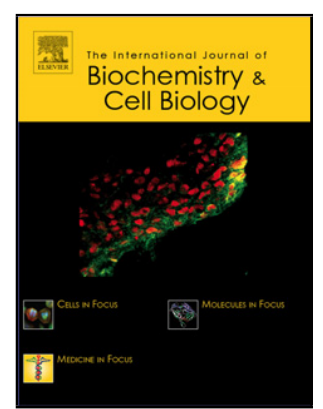

PII:

S1357-2725(18)30123-7

DOI: https://doi.org/10.1016/j.biocel.2018.05.011

Reference: BC 5368

To appear in: The International Journal of Biochemistry \& Cell Biology

Received date: $20-12-2017$

Revised date: $4-5-2018$

Accepted date: 21-5-2018

Please cite this article as: Khan TF, Price BL, Morgan PB, Maldonado-Codina C, Dobson $\mathrm{CB}$, Cellular fluorescein hyperfluorescence is dynamin-dependent and increased by Tetronic 1107 treatment, International Journal of Biochemistry and Cell Biology (2018), https://doi.org/10.1016/j.biocel.2018.05.011

This is a PDF file of an unedited manuscript that has been accepted for publication. As a service to our customers we are providing this early version of the manuscript. The manuscript will undergo copyediting, typesetting, and review of the resulting proof before it is published in its final form. Please note that during the production process errors may be discovered which could affect the content, and all legal disclaimers that apply to the journal pertain. 
Cellular fluorescein hyperfluorescence is dynamin-dependent and increased by Tetronic 1107 treatment

Tahmina F. Khan ${ }^{\mathrm{a}, \mathrm{b}}$, Bianca L. Price ${ }^{\mathrm{a}}$, Philip B. Morgan ${ }^{\mathrm{b}}$, Carole MaldonadoCodina $^{\mathrm{b}}$, and Curtis B. Dobson ${ }^{\mathrm{a}^{*}}$.

a. Medical Device Biology Group, Faculty of Biology, Medicine and Health, The University of Manchester, UK

b. Eurolens Research, Faculty of Biology, Medicine and Health, The University of Manchester, UK

*Corresponding author: Professor Curtis B Dobson, Medical Device Biology Group, Faculty of Biology Medicine and Health, The University of Manchester, Oxford Road, Manchester, M13 9PT, UK.

E-mail: curtis.b.dobson@manchester.ac.uk. Phone: +44(0)161306 8765

\section{Highlights}

- Clinical solution-induced corneal staining can be reproduced in an in vitro model

- Increased fluorescein uptake does not correlate with necrotic or apoptotic cells

- Dynasore, an inhibitor of dynamin, reduces cellular uptake of fluorescein

- Surfactant Tetronic 1107 increases fluorescein uptake whereas Triton X-100 does not 


\section{Abstract}

Sodium fluorescein ('fluorescein') staining of the ocular surface is frequently an indicator of compromised ocular health, and increases in the presence of certain contact lens multi-purpose solutions (MPS), a phenomenon known as solution induced corneal staining (SICS). The mechanism(s) underpinning fluorescein hyperfluorescence are uncertain, though may reflect increased cellular uptake of fluorescein by corneal epithelial cells. We have developed an in vitro model to study fluorescein uptake in both 'generic' mammalian cells (murine fibroblasts) and human corneal cells. Fluorescein hyperfluorescence increased after treatment with two MPS associated with clinical corneal fluorescein staining, yet there was no cellular hyperfluorescence for two MPS that do not cause this staining. Increased fluorescein uptake did not correlate with presence of a necrotic or an apoptotic marker (propidium iodide and Caspase-3 respectively). Incubation of MPS-treated cells with dynasore (an inhibitor of dynamin, implicated in endocytic pathways) reduced fluorescein uptake irrespective of MPS treatment. The non-ionic surfactant Tetronic 1107 (present in both MPS associated with corneal fluorescein staining) increased uptake of fluorescein for both cell types, whereas an unrelated surfactant (Triton X-100) did not. We conclude that the clinical hyperfluorescence profile observed after exposure to four MPS can be reproduced using a simple model of cellular fluorescein uptake, suggesting this is the biological basis for SICS. Fluorescein entry does not correlate with necrosis or apoptosis, but instead involves a dynamin-dependent active process. Moreover the surfactant Tetronic 1107 appears to be a key MPS constituent triggering increased fluorescein entry, and may be the major factor responsible for SICS. 
Keywords: Fluorescein; Solution induced corneal staining (SICS); Surfactants; Multi-purpose solutions (MPS); Fluorescein uptake

\section{Introduction}

Sodium fluorescein ('fluorescein') is frequently used in cell biological research, and as a diagnostic tool in ophthalmology and optometry, where it indicates the integrity of the corneal and conjunctival surfaces. When hyperfluorescence (staining) is observed, it is assumed to indicate dead or damaged cells (G. Wilson et al. 1995; Tabery 1992; Tabery 2003a; Tabery 2003b). However, the cellular basis for this staining is uncertain, and may reflect physiological changes unrelated to cellular damage (Bandamwar et al. 2014; Bakkar et al. 2014). Corneal staining is typically observed with pre-existing conditions such as keratoconjunctivitis sicca (dry eye) (Jie et al. 2008; McMonnies 2007), following trauma such as alkali burns or corneal abrasions (Wipperman \& Dorsch 2013; Fante \& Trobe 2014; S. A. Wilson \& Last 2004; Smally et al. 1992; Scarlett \& Gee 2007), contact lens wear, and with the use of certain contact lens care solutions (Andrasko \& Ryen 2008; Carnt, Willcox, et al. 2007). It remains unclear whether increased fluorescein intensity is localised on the corneal surface, within or between epithelial cells, or within the stroma. It has been suggested that fluorescein can be internalised by epithelial cells (Mokhtarzadeh et al. 2011; Bandamwar et al. 2014) and that it is the increased localisation of fluorescein within the cell that is observed as hyperfluorescence.

Many recent reports have described the phenomenon of solution induced corneal staining (SICS) associated with soft contact lens wear (Efron 2013; Andrasko \& Ryen 2008; Carnt, Willcox, et al. 2007; Carnt et al. 2009; Carnt, Jalbert, et al. 2007; 
Morgan \& Maldonado-Codina 2009; Ward 2008). SICS presents as superficial corneal and conjunctival staining, consistent with single (or clusters of) cells appearing brighter than adjacent cells (Maldonado-Codina et al. 2013). The intensity is greatest 1-2 hours after exposure to certain soft lens / multipurpose solution (MPS) combinations (Bandamwar et al. 2010; Garofalo et al. 2005; Andrasko \& Ryen 2008; Lebow \& Schachet 2003). MPS is formulated to both clean and disinfect re-useable contact lenses and characteristically contains a surfactant cleaner (e.g. a poloxamine block copolymer such as Tetronic 1107), a biocide such as Polyhexamethylene biguanide (PHMB) or Polyquaternium-1 (PQ1) and a buffering agent (e.g. citrate, phosphate, or borate).

Certain lens/MPS combinations induce notable cytotoxic effects in vitro (Choy et al. 2012; Wright \& Mowrey-McKee 2005; Dutot et al. 2008; Dutot et al. 2010), although there is little evidence linking this to fluorescein hyperfluorescence. More broadly it is uncertain whether any cellular damage has occurred when hyperfluorescence is observed in vivo. For example, exposure to PHMB-based MPS, most commonly associated with SICS resulted in no histological change when observed using scanning electron microscopy (SEM) (Tchao et al. 2002). Conversely, after exposure to PQ-1-based MPS, typically not associated with increased hyperfluorescence, both membrane disruption and increased membrane permeability was observed (Tchao et al. 2002). It has been suggested that SICS is a benign phenomenon which is not indicative of dead or damaged cells (MaldonadoCodina et al. 2013). It is noteworthy that studies of MPS-associated hyperfluorescence predominately focus on the effects of biocides, and there is little 
exploration of the potential hyperfluorescence-inducing effects of other MPS components.

An in vitro model of SICS potentially provides a useful tool to investigate a) the biological basis of the interaction of epithelial cells with fluorescein and b) a basic understanding of the clinical SICS response. A convincing laboratory model of SICS should exhibit similar hyperfluorescence responses to those observed clinically. Our laboratory has previously developed such models utilising multiple cell types and has shown that fluorescein is taken into cells resulting in hyperfluorescence in response to treatment with a single MPS (Bakkar et al. 2014). We also demonstrated that internalisation and efflux of fluorescein are both energy dependent processes (Bakkar et al. 2014).

The present study aimed to test this model further by confirming that the presence or absence of hyperfluorescence associated with clinical use of four different MPS is also found in our model system. We additionally aimed to clarify the likely mechanisms underlying SICS by investigating whether any hyperfluorescence caused by these solutions is associated with increased apoptosis or endocytosis. There are numerous endocytic pathways that involve dynamin (a GTPase protein) and the actin cytoskeleton. These components in particular are integral to the invagination of the plasma membrane and the movement of endocytic vesicles (that contain extracellular materials) into the cell (Jeng \& Welch 2001). Dynamin is a GTPase implicated in several endocytic pathways, and has also been linked to actin cytoskeleton activity (Jeng \& Welch 2001; Doherty \& McMahon 2009). Both processes are integral to vesicle formation and uptake of extracellular materials into 
the cell body. Dynasore is a well-known inhibitor of dynamin (Tsai et al. 2009; Barrias et al. 2010; Yamada et al. 2009; Macia et al. 2006), and so this was used to investigate dynamin-associated endocytic pathways as a potential mechanism for fluorescein uptake. Finally, we aimed to identify the component(s) of MPS responsible for inducing hyperfluorescence.

\section{Materials and Methods}

\subsection{Cell culture}

Human corneal (HC) cells were obtained from human corneal explants provided by Manchester Eye Bank. Briefly, HC cells were grown from segmented sections of corneal explants in wells pre-coated for 1 hour with $0.01 \%$ calf-skin type I collagen (Sigma-Aldrich, UK) prepared in Dulbecco's PBS (PBS) (ThermoFisher, UK) (adapted from Kahn et al. 1993). Murine fibroblasts (L929 cells) (ECAAC, UK) and $\mathrm{HC}$ cells were maintained at $37^{\circ} \mathrm{C}$ and $5 \% \mathrm{CO}_{2}$ with Dulbecco's Modified Eagle Medium (DMEM) containing 4500 $\mathrm{mg}^{-\mathrm{L}}$ glucose (Sigma-Aldrich, UK) supplemented with $10 \%$ v/v fetal bovine serum (FBS) (Sigma-Aldrich, UK) and 4mM L-glutamine (Gibco by Life Technologies, UK), referred to hereafter as 'growth medium'. For $\mathrm{HC}$ cells, all tissue culture plasticware had been pre-coated for 1 hour with $0.01 \%$ calf-skin type I collagen in PBS. Cells were maintained until they reached approximately $80 \%$ confluency, before rinsing with PBS and treating with $0.25 \%$ trypsin-EDTA (Life Technologies, UK) for L929 cells or $0.05 \%$ trypsin-EDTA in PBS for HC cells, and later neutralisation of trypsin-EDTA with growth medium. For experiments, cells were seeded in 24-well plates (Sigma-Aldrich, UK) at a density of $1 \times 10^{5} \mathrm{cell} /$ well for fluorescence microscopy, or in 96 well plates (SigmaAldrich, UK) at $2.5 \times 10^{4}$ cells/well for high content analysis (HCA) or cell viability 
experiments, and in CELLview ${ }^{\mathrm{TM}}$ glass bottom dishes (Greiner Bio-One, UK) at $5 \times 10^{4}$ cells per chamber for confocal microscopy.

\subsection{Cell treatment with MPS, BKC, or MPS components}

MPS formulations were obtained commercially, based on their differential association with SICS, and their main biocide and surfactants components (shown in Table 1). MPS known to cause hyperfluorescence were: ReNu Multi-purpose Solution Sensitive ${ }^{\circledR}$ and Biotrue ${ }^{\circledR}$ (Baush + Lomb, Kingston up Thames, UK) referred to as P-1107 and P-PQ1-1107 respectively. MPS investigated which do not cause hyperfluorescence were: Complete RevitaLens ${ }^{\circledR}(\mathrm{AMO}$, High Wycombe, UK) referred to as PQ1-Alex-904, and Opti-Free Replenish ${ }^{\circledR}$ (Alcon, Surrey, UK) referred to as PQ1-Aldox-1304. In later experiments a 10\% w/v solution of Tetronic 1107 (BASF, New Jersey, USA) was prepared in borate buffer $(0.6 \%$ boric acid, $0.1 \%$ borax); borate buffer was used as this is the buffering system in use in P-PQ11107 and P-1107 formulations, and this was diluted to $1 \%$ (the concentration used in those MPS) and also $0.1 \%$ in borate buffer prior to addition to cells. A $1.25 \%$ solution of Triton X-100 (Sigma-Aldrich, UK) was diluted in PBS to produce $0.125 \%, 0.0125 \%$, and $0.00125 \%$ solutions. Finally $0.01 \% \mathrm{w} / \mathrm{v}$ benzalkonium chloride (BKC) (Sigma-Aldrich, UK) was prepared in PBS. For cell treatment media was removed and the various MPS or surfactant solutions were added, before incubation for 2 hours at $37^{\circ} \mathrm{C}$. BKC solution was added for 10 minutes at $37^{\circ} \mathrm{C}$ (a sufficient time to induce necrosis). Effects were compared with cells treated with growth medium alone, hereafter referred to as 'media control', or another appropriate control. 


\subsection{Fluorescein staining}

After treatment, test formulations were aspirated and cells incubated with $0.01 \% \mathrm{w} / \mathrm{v}$ fluorescein (Sodium fluorescein, Sigma-Aldrich, UK) in PBS for 10 minutes at $37^{\circ} \mathrm{C}$. Hoecsht 33342 , at a final concentration of $0.2 \mathrm{mg} / \mathrm{ml}$ in $\mathrm{PBS}$, was added to enable total cell counts (necessary for subsequent fluorescence intensity analysis). For some experiments, propidium iodide (PI) (Sigma-Aldrich, UK), at a final concentration of $0.01 \mathrm{mg} / \mathrm{ml}$ in PBS, was also added for 10 minutes to identify lysed cells. On removal from the incubator, plates were kept on ice, and cells washed three times with cold PBS; we had previously shown that low temperature was necessary to prevent fluorescein efflux (Bakkar et al. 2014). Cells remained on ice until microscopy or high content analysis (HCA) (always done within 5 minutes).

\subsection{Metabolic activity assays (MTT)}

HC or L929 cells growing in 96 well plates were treated with test formulations, before aspiration and replacement with growth medium containing $0.5 \mathrm{mg} / \mathrm{ml}$ thiazolyl blue tetrazolium bromide (MTT) (Sigma-Aldrich, UK), and subsequent incubation for 2 hours at $37^{\circ} \mathrm{C}$. This medium was aspirated, and insoluble formazan solubilised using $100 \mu$ l of DMSO (Sigma-Aldrich, UK), followed by assessment of absorbance at $555 \mathrm{~nm}$.

\subsection{Caspase-3 immunofluorescence}

L929 cells growing in 24 well plates were treated with MPS and fluorescein as described above. Cells were immunostained with an antibody for cleaved Caspase-3 (New England BioLabs, UK). After fixing for 10 minutes at room temperature in $3.7 \%$ w/v paraformaldehyde (Alfa Aesar, UK). A blocking buffer, (5\% Normal Goat 
Serum (New England BioLabs, 5425) and 0.3\% Triton X-100 (Sigma-Aldrich, UK) in PBS) was then applied for 60 minutes at $37^{\circ} \mathrm{C}$. The blocking buffer was aspirated and the primary antibody was diluted 1:400 in 1\% BSA (Sigma-Aldrich, UK) supplemented with $0.3 \%$ Triton $\mathrm{X}-100$ in PBS (antibody dilution buffer), and applied overnight at $4^{\circ} \mathrm{C}$. Plates were washed three times with $1 \mathrm{ml}$ PBS and incubating for 5 minutes before the addition of Alex Fluor 594 conjugated goat antirabbit IgG secondary antibody (ThermoFisher Scientific, UK) (diluted 1:250 in antibody dilution buffer), and incubated at room temperature in the dark for 2 hours. This was aspirated, and cells washed with $1 \mathrm{ml}$ PBS for 5 minutes, before observation using widefield fluorescent microscopy (Olympus IX83).

\subsection{Evaluation of dynamin-associated fluorescein staining}

Cells in 96-well plates were treated with MPS formulations or media for 2 hours and then rinsed with serum free media before addition of $160 \mu \mathrm{M}$ dynasore monohydrate in serum-free medium (dynasore) (Sigma-Aldrich, UK) for 30 minutes. Conditions of dynasore treatment were optimised by fluorescence microscopy analysis of pHRodo $^{\mathrm{TM}}$ red transferrin conjugate (Molecular Probes, Life Technologies, UK) uptake by L929 cells (after treatment at 40 to $160 \mathrm{uM}$ of dynasore for $30 \mathrm{~min}$ to $2 \mathrm{hr}$ ). The dynasore stock solution contained $0.1 \%$ DMSO, and a vehicle control was used in which cells were treated with serum-free medium containing 0.1\% DMSO. After aspiration, cells were incubated with $0.01 \% \mathrm{w} / \mathrm{v}$ fluorescein and washed as above. Fluorescein uptake was quantified using HCA. 


\subsection{High content analysis (HCA)}

Quantification of fluorescein uptake was carried out using the Cellomics Array Scan VTI HCS Reader and HCS Studio Cell 2.0 Analysis Software. Cells were visualised using the ArrayScan ${ }^{\mathrm{TM}}$ automated Observer $\mathrm{Z} 1$ inverted microscope (Zeiss) with transmitted light and fluorescence using an XF53 filter wheel. High-resolution images were taken using a CCD camera (Hamamatsu Orca ER) with a 5x/0.25 Fluar objective. Fluorescein stained cell images were taken using 0.033 seconds exposure. One field of view was taken per well, and multiple wells per treatment were tested. Samples were maintained at $4{ }^{\circ} \mathrm{C}$ during imaging to limit fluorescein loss from cells. Using a built in bioapplication, and adjusting for cell type, the mean pixel intensity of each cell was measured. The median fluorescence intensity value was reported in arbitrary units (AU) (median (lower 95\% CI - upper 95\% CI limit calculated for the median)).

\subsection{Fluorescence and Confocal microscopy}

Widefield fluorescent images of L929 cells were collected on an Olympus IX83 inverted microscope using a 10x / 0.3 UPlanFL N, or 20x / 0.45 LUC PlanFL N (Ph1) objective and captured using an Orca ER camera (Hamamatsu) with CellSens software (Olympus). Confocal images of L929 and HC were collected on a Leica TCS SP8 AOBS inverted gSTED microscope using a 40x / 1.3 HC PL APO (Oil) objective. The confocal settings were set as pinhole 1.12 airy unit and scan speed $400 \mathrm{~Hz}$ unidirectional. Images were processed using ImageJ. 


\subsection{Statistical analysis}

All fluorescein fluorescence intensity data are presented as the median intensity values, and error bars represent $95 \%$ confidence intervals (CI) calculated for the median. Metabolic activities are presented as a percentage of the appropriate control and the associated CI, calculated using the median metabolic activity values. In all instances, data were analysed using non-parametric Kruskal-Wallis ANOVA and Dunn's multiple comparison post-hoc tests. The level of statistical analysis was set to $* \mathrm{p}=0.05, * * \mathrm{p}=0.01$ and $* * * \mathrm{p} \leq 0.001$.

\section{Results}

3.1. Fluorescein hyperfluorescence in vitro is increased by the same MPS formulations associated with SICS.

L929 cells treated with P-PQ1-1107 and P-1107 (MPS formulations both associated with hyperfluorescence clinically) showed increased fluorescein uptake compared to media control, and an increase in PI staining for P-PQ1-1107 only (confirming a lack of cell death for P-1107, and increased late-stage apoptosis or necrosis after treatment with P-PQ1-1107). Those formulations associated clinically with low fluorescein hyperfluorescence (PQ1-Aldox-1304 and PQ1-Alex-904) also caused low fluorescein hyperfluorescence in our model, although increased PI staining was observed for both, suggesting increased late-stage apoptosis or necrosis after treatment with these solutions (Figure 1A).

Fluorescein uptake was quantified using HCA with L929 cells and HC cells, and as its intensity was not normally distributed, median values and the lower 95\% CI - 
upper $95 \%$ CI of the median were calculated. Intensities after treatment of L929 cells with P-PQ1-1107 and P-1107 were significantly greater than media control (84.5 (78.2-92.3), 119.1 (111.1-126.5) and 61.7 (50.1-71.8) respectively). However for PQ1-Aldox-1304 and PQ1-Alex-904 treatment, intensity was significantly less than media control (10.2 (9.5-10.8) and $0(0-0)$ (Figure 1B). Similar results were obtained for $\mathrm{HC}$ cells; after P-PQ1-1107 and P-1107 treatment intensity significantly increased when compared to media control (655 (641.3-676.5), 509.9 (492.8-524.6) and 187.5 (180.8-192) respectively) whereas for PQ1-Aldox-1304 and PQ1-Alex904 intensity decreased (78 (73.2-85.1) and 66 (62.4-71.2) respectively) (Figure 1C). In all instances $\mathrm{p}<0.0001$.

\subsection{MPS associated with hyperfluorescence cause no change in metabolic} activity.

Treatment with cytotoxic levels of BKC resulted in necrosis and minimal fluorescein staining in L929 cells (Figure 2A). MTT assays showed that BKC treated L929 cells retained only $4.4 \%(4-6.6 \%)$ the metabolic activity of control cells $(p=0.005)$. Similarly PQ1-Alex-904 and PQ1-Alex-904+FL treated cells showed 6.4\% activity of the control $(\mathrm{p}<0.001)$. PQ1-Aldox-1304 and PQ1-Aldox-1304+FL treated cells also showed lower metabolic activity (not statistically different from control). No significant change in metabolic activity was found for fluorescein, P-PQ1-1107 or P-1107 treatment (Figure 2B).

Metabolic activity in $\mathrm{HC}$ cells also decreased after BKC treatment to 8.6\% (4.5-9.6\%) of control; ( $\mathrm{p}=0.003)$. PQ1-Alex-904 and PQ1-Alex-904+FL treated cells showed decreases to $9.6 \%(8.9-11.1 \%)$ and $4.7 \%(4.4-7.3 \%)$ of control respectively $(\mathrm{p} \leq 0.001)$. 
PQ1-Aldox-1304 and PQ1-Aldox-1304+FL decreased to 13.7 (11.5-15.1\%) and 20.8\% $(14.1-26.1 \%)$ of control respectively $(\mathrm{p} \leq 0.03)$. No significant change in metabolic activity was seen after treatment with fluorescein, P-PQ1-1107 or P-1107 (Figure 2C).

\subsection{MPS induced fluorescein hyperfluorescence is not associated with apoptosis.}

L929 cells and HC cells treated with media control and MPS were examined by confocal microscopy. Membrane blebbing (a hallmark of apoptosis) was observed for P-PQ1-1107 treatment but not after media control or P-1107 treatment. Since both these MPS are associated with hyperfluorescence, these data suggest apoptosis and hyperfluorescence may be distinct processes (Figure 3A). To examine further, L929 cells treated with various MPS formulations and fluorescein were examined for apoptosis by immunostaining for cleaved caspase-3. With all MPS treatments, no clear evidence of caspase-3 staining above media control levels was apparent (Figure 3B), indicating no correlation between hyperfluorescence and apoptosis.

\subsection{Fluorescein staining in L929 and HC cells is associated with dynamin- dependent pathways.}

Dynasore treatment resulted in decreased fluorescein intensity in control L929 cells and after treatment with hyperfluorescence-inducing MPS formulations $(\mathrm{p}<0.0001$ in all instances) (Figure 4A). The same effect was also seen in $\mathrm{HC}$ cells, with a significant decrease in dynasore treated cells (Figure 4B) $(\mathrm{p} \leq 0.002)$. No significant difference in cell numbers was found after treatment with or without dynasore for both control or MPS-treated cells. Additionally, metabolic activity measured for cells treated under identical conditions was measured by MTT assay. No significant 
decrease was found (Figure 4C and 4D respectively), confirming that the decreased fluorescein intensity seen after dynasore treatment was not simply an artefact related to a toxic effect of dynasore itself.

\subsection{Increased fluorescein fluorescence is related to the surfactant Tetronic} 1107.

The two solutions causing increased fluorescein hyperfluorescence both contain Tetronic 1107, and so we tested whether this might cause hyperfluorescence, both above and below its critical micelle concentration $(\mathrm{CMC})(\mathrm{CMC}=0.49 \% \mathrm{w} / \mathrm{v}$ at $\mathrm{pH}$ 7.4 (Chiappetta et al. 2008)). Cells were treated with Tetronic 1107 at $0.1 \%, 1 \%$ and $10 \% \mathrm{w} / \mathrm{v}$ for 2 hours before fluorescein treatment. Fluorescein fluorescence intensity in L929 cells increased with $0.1 \%, 1 \%$ and $10 \%$ w/v Tetronic 1107 compared to both borate buffer (carrier control) and media control ( $\mathrm{p}<0.0001$ in all instances) (Figure $5 \mathrm{~A})$. There was a small but significant increase in fluorescence intensity after $1 \%$ Tetronic 1107 treatment to 642.5 (632.5-653.3) compared to cells treated with PPQ1-1107 at 604.5 (584-621.4); $\mathrm{p}<0.0001)$. As expected the median fluorescence intensity decreased for PQ1-Aldox-1304 and PQ1-Alex-904 treatments relative to both buffer and media control $(\mathrm{p}<0.0001)$.

In $\mathrm{HC}$ cells, $1 \%$ w/v Tetronic 1107 treatment significantly increased the median fluorescein fluorescence intensity to 227.3 (215.2-238.8) as compared with borate buffer treatment and media control ( $\mathrm{p}<0.0001$ in both instances). The fluorescence intensity found for $1 \% \mathrm{w} / \mathrm{v}$ Tetronic 1107 also significantly exceeded the intensity measured for PQ1-Aldox-1304, PQ1-Alex-904, 0.1\% w/v and 10\% w/v Tetronic 
1107, however were less than the median fluorescence intensity values found for PPQ1-1107 and P-1107 ( $\mathrm{p}<0.0001$ in all instances) (Figure 5B).

The effect on fluorescein fluorescence of treatment with the generic surfactant Triton X-100 was also measured in $\mathrm{HC}$ cells (Figure 5C). The CMC for Triton X-100 occurs between 0.125 to $0.563 \%(\mathrm{v} / \mathrm{v})$. Fluorescein fluorescence intensities after $1.25 \%, 0.125 \%$ and $0.0125 \%$ Triton $\mathrm{X}-100$ treatment were significantly less than after PBS treatment of $\mathrm{HC}$ cells $(\mathrm{p}<0.0001$ in all instances). The fluorescence intensity after $0.00125 \%$ Triton X-100 treatment of HC cells was comparable to that of PBS treated cells ( $>>0.9999)$. Treatment with $0.00125 \%$ and $0.0125 \%$ Triton X100 significantly increased fluorescein fluorescence intensity to 307.8 (298-313.5) and 244.6 (240.8-249.6) respectively relative to media control (212.8 (207.9-216.5)) whereas after treatment with $0.125 \%$ and $1.25 \%$ Triton X-100 (concentrations above its $\mathrm{CMC})$ a decrease in fluorescein fluorescence intensity to $32.5(31.2-34.8)$ and $22.6(22.4-22.8)$ respectively was observed ( $<<0.0001$ in all instances).

\subsection{Surfactant-induced hyperfluorescence is not mediated by increased metabolic activity.}

The effects of Tetronic 1107 and Triton X-100 on cell metabolic activity was examined to confirm that surfactant-induced hyperfluorescence was not mediated through increased cellular activity. We found that $0.1 \%, 1 \%$, and $10 \% \mathrm{w} / \mathrm{v}$ Tetronic 1107 treatments resulted in no significant change in metabolic activity for L929 cells ( $p>0.9999$ in all instances) and for $\mathrm{HC}$ cells ( $\mathrm{p} \geq 0.6$ ) (Figures 5D and E respectively).

The effect of Triton X-100 on HC cell metabolic activity was also measured. No significant change in metabolic activity was observed with fluorescein only, PBS+FL, 
$0.00125 \%$ and $0.0125 \%$ Triton $\mathrm{X}-100+\mathrm{FL}$ treatments ( $>0.999$ in all instances). However, with $0.125 \%$ and $1.25 \%$ Triton $\mathrm{X}-100$ treatment metabolic activity significantly decreased to $1.9 \%(1.7-2 \%)$ and $1.5(1.2-2 \%)$ respectively; $(\mathrm{p}=0.01$ and $\mathrm{p}=0.003$ respectively) (Figure $5 \mathrm{~F})$.

\section{Discussion}

We have developed an in vitro model to investigate the biological basis for corneal fluorescein hyperfluorescence. Our approach made use of the well-characterised clinical effects of different contact lens MPS on fluorescein hyperfluorescence (known as SICS). Fluorescein hyperfluorescence may involve the direct uptake of fluorescein into corneal epithelial cells (Mokhtarzadeh et al. 2011; Kuwayama et al. 2002; Bandamwar et al. 2014). We previously showed that fluorescein uptake by cells was temperature dependent, and increased after exposure to ReNu Multiplus ${ }^{\circledR}$ MPS, which contains Tetronic 1107 like P-1107 (Bakkar et al. 2014). In the present study, we examined the effects of MPS known to increase or decrease hyperfluorescence clinically, and further examined the biological basis for fluorescein uptake. We tested this after a 2 hour exposure to MPS, which clinically is the exposure time typically found to produce maximal corneal staining, and which is the exposure time used in the Andrasko Staining Grid (Andrasko \& Ryen 2008).

Notably we performed fluorescein quantification using a high content analysis (HCA) platform which measures fluorescence levels in each cell. MPS formulations associated with increased hyperfluorescence on the ocular surface (P-PQ1-1107 and P-1107) (Jones et al. 2002; Andrasko \& Ryen 2008; Tilia et al. 2012) both cause 
increased fluorescein hyperfluorescence in cells. Conversely PQ1-Alex-904 or PQ1Aldox-1304 resulted in little or no fluorescein staining, also as is found clinically (Kilvington et al. 2010; Tilia et al. 2012). The interaction of a contact lens material itself with the MPS may contribute to the hyperfluorescence observed clinically. However our finding that the clinically observed effects of these four MPS can be reproduced without the presence of a lens, suggests that SICS may primarily involve the biochemical effects of the MPS alone.

Non-viable necrotic cells (following BKC treatment) are unable to take up fluorescein, consistent with our previous findings (Bakkar et al. 2014) and with those of Bandamwar et al who reported minimal fluorescein fluorescence in non-viable human corneal limbal epithelial (HCLE) cells (Bandamwar et al. 2014). Interestingly MPS formulations P-PQ1-1107 and P-1107, both of which are associated with clinical hyperfluorescence, produced limited or no increased PI staining respectively and no significant decreases in metabolic activity. Conversely, significant loss in metabolic activity was found with the MPS formulations PQ1Alex-904 and PQ1-Aldox-1304, both of which are clinically associated with low levels of fluorescence. In contrast with the view that fluorescein hyperfluorescence reflects 'toxicity staining', fluorescein staining appears in fact to associate with an absence of cytotoxicity. Staining on the ocular surface may therefore not indicate dead cells, but instead metabolically fully functional cells. The presence of MPS increases fluorescein staining in these living cells. In the later stages of our study we examined what processes - presumably stimulated by MPS P-PQ1-1107 and P-1107 - may be responsible for this hyperfluorescence. 
Notably we did not find clear evidence for any of the test MPS formulations resulting in increased staining for Caspase-3, which is a vital downstream protease in the apoptosis pathway (Li \& Yuan 2008; Mcllwain et al. 2013), suggesting hyperfluorescence does not correlate with apoptosis. Interestingly, blebbing (a morphological change of the cell membrane associated with apoptosis (Mills et al. 1998; Ziegler \& Groscurth 2004)) occurred in P-PQ1-1107 treated cells, although not after P-1107 treatment, even though both increase hyperfluorescence in vitro and in vivo, further suggesting apoptosis and hyperfluorescence are distinct processes. The lack of increased Caspase-3 staining after P-PQ1-1107-treatment suggests the apparent apoptosis indicated by blebbing in P-PQ1-1107-treated cells has progressed beyond the early-stages at the time of assay (further work with specific markers for late-stage apoptosis would confirm this).

We previously reported that fluorescein cellular uptake and egress are active processes (Bakkar et al. 2014). We investigated this further here by directly inhibiting dynamin-dependent pathways using dynasore, a reversible inhibitor of dynamin, and found decreased fluorescein uptake for both control and MPS-treated cells. These data suggest dynamin and its associated actin binding proteins are directly involved in fluorescein cellular entry. However, as fluorescein uptake was not completely inhibited by dynasore, it is possibly other endocytic pathways independent of dynamin may also contribute.

We finally examined which MPS components may increase the active internalisation of fluorescein. The non-ionic surfactant Tetronic 1107 is present in both P-PQ11107 and P-1107 (the MPS which increase fluorescein staining) and has the lowest 
ethylene oxide to propylene oxide ratio and is thus highly hydrophilic, in contrast to the less hydrophilic surfactants Tetronics 904 and 1304, which are present in PQ1Alex-904 and PQ1-Aldox-1304 respectively (Table 2) (Alvarez-Lorenzo et al. 2010).

Our finding that hyperfluorescence intensity increases significantly after treatment with 1\% (w/v) Tetronic 1107 (the concentration in P-PQ1-1107 and P-1107) suggest Tetronic 1107 is a key mediator of hyperfluorescence caused by these MPS. Tetronic 1107 forms polymeric micelles which are more stable and less damaging to the lipid bilayer than typical surfactant micelles (Sandez-Macho et al. 2015). Polymeric micelles encapsulate and solubilise otherwise poorly water-soluble drugs, and block copolymers have drug delivery properties (Alakhov et al. 1996; Harada \& Kataoka 1998; Cammas et al. 1997). Polymeric micelle uptake is time-, pH-, energy-, and temperature-dependent (Allen et al. 1999; Luo et al. 2002), with localisation to cytoplasmic organelles (Savic et al. 2003), and may be mediated by endocytosis (Allen et al. 1999; Luo et al. 2002; Savic et al. 2003). Our finding of a role for Tetronic 1107 in increasing fluorescein hyperfluorescence, is therefore consistent with our identification of dynamin-dependent processes (which include endocytosis) as a key mediator of MPS-induced fluorescein hyperfluorescence.

In contrast, we found the surfactant Triton X-100 does not induce increased fluorescein uptake in $\mathrm{HC}$ cells when used at levels above its $\mathrm{CMC}$, suggesting Tetronic 1107 induced hyperfluorescence may be specific to this block copolymer, and cannot be replicated with a similarly non-ionic surfactant. Triton X-100 causes cell lysis (Koley \& Bard 2010), consistent with our finding of a significant decrease in metabolic activity after treatment. This may counteract any increase in 
hyperfluorescence (in line with our previous findings that non-viable cells exhibit minimal hyperfluorescence).

Our study is the first to investigate the effects of surfactants on fluorescein uptake, and suggests that hyperfluorescence could be attributed to the surfactant component in MPS formulations. Although interactions of the other MPS components in these solutions and the presence of a contact lens may contribute to the overall hyperfluorescence, our data implicate Tetronic 1107 effects on active uptake processes in the cells as being central to SICS. More broadly our findings suggest that active dynamin-dependent processes may be a key component of corneal fluorescein hyperfluorescence caused by a variety of stimuli.

\section{Acknowledgements}

We thank Dr Gareth Griffiths from Imagen Therapeutics for assistance with High Content Analysis experiments, and the The Bioimaging Facility (The University of Manchester) for microscopy advice. This work was supported by a grant from the BBSRC and CooperVision. 


\section{References}

Alakhov, V.Y., Moskaleva, E.Y., Batrakova, E.V., Kabanov, A.V., 1996. Hypersensitization of Multidrug Resistant Human Ovarian Carcinoma Cells by Pluronic P85 Block Copolymer. Bioconjugate Chemistry, 7(2), pp.209-216. doi: $10.1021 / \mathrm{bc} 950093 \mathrm{n}$

Allen, C., Yu, Y., Eisenberg, A., Maysinger, D., 1999. Cellular internalization of PCL(20)-b-PEO(44) block copolymer micelles. Biochimica Et Biophysica ActaBiomembranes, 1421(1), pp.32-38. doi: 10.1016/S0005-2736(99)00108-X

Alvarez-Lorenzo, C., Rey-Rico, A., Sosnik, A., Taboada, P., Concheiro, A., 2010. Poloxamine-based nanomaterials for drug delivery. Frontiers Bioscience. 1(2), pp424-40.

Andrasko, G., Ryen, K., 2008. Corneal staining and comfort observed with traditional and silicone hydrogel lenses and multipurpose solution combinations. Optometry, 79(8), pp.444-454. doi: 10.1016/j.optm.2008.04.097.

Bakkar, M.M.., Hardaker,, L., March, P., Morgan, P.B., Maldonado-Codina, C., Dobson, C.B., 2014. The cellular basis for biocide-induced fluorescein hyperfluorescence in mammalian cell culture. S. Fleiszig, ed. PLoS ONE, 9(1), p.e84427. doi:10.1371/journal.pone.0084427 
Bandamwar, K.L., Garrett, Q., Cheung, D., Huang, J., Lee, L., Ng, Carina., Papas, E.B., 2010. Onset time course of solution induced corneal staining. Contact Lens and Anterior Eye, 33(4), pp.199-201. doi: 10.1016/j.clae.2010.02.004

Bandamwar, K.L., Papas, E.B., Garrett, Q., 2014. Fluorescein staining and physiological state of corneal epithelial cells. Contact Lens and Anterior Eye, 37(3), pp.213-223. doi: 10.1016/j.clae.2013.11.003

Barrias, E.S., Reignault, L.C., De Souza, W., Carvalho, T.M.U., 2010. Dynasore, a Dynamin Inhibitor, Inhibits Trypanosoma cruzi Entry into Peritoneal Macrophages P. T. Bozza, ed. PLoS ONE, 5(1), p.e7764. doi: 10.1371/journal.pone.0007764

Cammas, S., Matsumoto, T., Okano, T., Sakurai., Y, Kataoka, K., 1997. Design of functional polymeric micelles as site-specific drug vehicles based on poly ( $\alpha$ hydroxy ethylene oxide-co- $\beta$-benzyl 1-aspartate) block copolymers. Materials Science and Engineering, 4(4), pp.241-247. doi: 10.1016/S0928-4931(97)00007-6

Carnt, N., Jalbert, I., Stretton, S., Naduvilath, T., Papas, E., 2007. Solution Toxicity in Soft Contact Lens Daily Wear Is Associated With Corneal Inflammation. Optometry and Vision Science, 84(4), pp.309-315. doi: 10.1097/OPX.0b013e318046551b

Carnt, N., Willcox, M.D.P., Evans, V., Naduvilath, T.J., Tilia, D., Papas, E.B., Sweeney, D.F., Holden, B.A., 2007. Corneal Staining: The IER Matrix Study. Contact Lens Spectrum, pp.38-43. Available at: 
https://www.clspectrum.com/issues/2007/september-2007/corneal-staining-the-iermatrix-study [Accessed March 27, 2017].

Carnt, N.A., Evans, V.E., Naduvilath, T.J., Willcox, M.D.P., Papas, E.B., Frisch, K.D., Holden, B.A., 2009. Contact lens-related adverse events and the silicone hydrogel lenses and daily wear care system used. Archives of Ophthalmology (Chicago, Ill.: 1960), 127(12), pp.1616-1623. doi: 10.1001/archophthalmol.2009.313

Chiappetta, D.A., Degrossi, Jose., Teves, S., D'Aquino, M., Bregni, C., Sosnik, A., 2008. Triclosan-loaded poloxamine micelles for enhanced topical antibacterial activity against biofilm. European Journal of Pharmaceutics and Biopharmaceutics, 69(2), pp.535-545. doi: 10.1016/j.ejpb.2007.11.021

Choy, C.K., Cho, P., Boost, M.V., 2012. Cytotoxicity and effects on metabolism of contact lens care solutions on human corneal epithelium cells. Clinical and Experimental Optometry, 95(2), pp.198-206. doi: 10.1111/j.14440938.2011.00687.x

Doherty, G.J., McMahon, H.T., 2009. Mechanisms of Endocytosis. Annual Review of Biochemistry, $\quad$ 78(1), pp.857-902. doi: 10.1146/annurev.biochem.78.081307.110540

Dutot, M., Warnet, J-M., Baudoin, C., Rat, P., 2008. Cytotoxicity of contact lens multipurpose solutions: Role of oxidative stress, mitochondrial activity and P2X7 
cell death receptor activation. European Journal of Pharmaceutical Sciences, 33(2), pp.138-145. doi: 10.1016/j.ejps.2007.10.006

Dutot, M., Reveneau, E., Pauloin, T., Fagon, R., Tanter, C., Warnet, J-M., Rat, P., 2010. Multipurpose Solutions and Contact Lens: Modulation of Cytotoxicity and Apoptosis on the Ocular Surface. Cornea, 29(5), pp.541-549. doi: 10.1097/ICO.0b013e3181bd4bc1

Efron, N., 2013. Putting vital stains in context. Clinical and Experimental Optometry, 96(4), pp.400-421. doi: 10.1111/j.1444-0938.2012.00802.x

Fante, R.J., Trobe, J.D., 2014. Bilateral Corneal Abrasions from Airbag Deployment. New England Journal of Medicine, 370(26), pp.e40-1. doi: 10.1056/NEJMicm1313137

Garofalo, R.J., Dassanayake, N., Carey, C., Stein, J., Stone, R., Robin, D., 2005. Corneal staining and subjective symptoms with multipurpose solutions as a function of time. Eye \& Contact Lens-Science and Clinical Practice, 31(4), pp.166-174. doi: 10.1097/01.ICL.0000152489.99455.DB

Harada, A., Kataoka, K., 1998. Novel Polyion Complex Micelles Entrapping Enzyme Molecules in the Core: Preparation of Narrowly-Distributed Micelles from Lysozyme and Poly(ethylene glycol)-Poly(aspartic acid) Block Copolymer in Aqueous Medium. Macromolecules, 31(2), pp.288-294. doi: 10.1021/ma971277v 
Jeng, R.L., Welch, M.D., 2001. Cytoskeleton: actin and endocytosis--no longer the weakest link. Current Biology: CB, 11(17), pp.R691-4. doi: 10.1016/S09609822(01)00410-9

Jie, Y., Xu, L., Wu, YY., Jonas, JB., 2008. Prevalence of dry eye among adult Chinese in the Beijing Eye Study. Eye, 23(3), pp.688-693. doi: 10.1038/sj.eye.6703101

Jones, L., Macdougall, N., Sorbara, L.G., 2002. Asymptomatic Corneal Staining Associated with the Use of Balafilcon Silicone-Hydrogel Contact Lenses Disinfected with a Polyaminopropyl Biguanide-Preserved Care Regimen. Optometry and Vision Science, 79(12), p.753.

Kahn, C.R., Young, E., Lee, H.I., Rhim, J.S., 1993. Human corneal epithelial primary cultures and cell lines with extended life span: in vitro model for ocular studies. Investigative Ophthalmology \& Visual Science, 34(12), pp.3429-3441.

Kilvington, S., Huang, L., Kao, E., Powell, C.H., 2010. Development of a new contact lens multipurpose solution: Comparative analysis of microbiological, biological and clinical performance. Journal of Optometry, 3(3), pp.134-142. doi: $10.1016 /$ S1888-4296(10)70019-4

Koley, D., Bard, A.J., 2010. Triton X-100 concentration effects on membrane permeability of a single HeLa cell by scanning electrochemical microscopy (SECM). 
Proceedings of the National Academy of Sciences, 107, pp.16783-16787. doi: 10.1073/pnas.1011614107

Kuwayama, K., Miyauchi, S., Tateoka, R., Abe, H., Kamo, N., 2002. Fluorescein uptake by a monocarboxylic acid transporter in human intestinal Caco-2 cells. Biochemical Pharmacology, 63(1), pp.81-88. doi: 10.1016/S0006-2952(01)00853-X

Lebow, K.A., Schachet, J.L., 2003. Evaluation of corneal staining and patient preference with use of three multi-purpose solutions and two brands of soft contact lenses. Eye \& Contact Lens-Science and Clinical Practice, 29(4), pp.213-220. doi: 10.1016/S0006-2952(01)00853-X

Li, J., Yuan, J., 2008. Caspases in apoptosis and beyond. Oncogene, 27(48), pp.6194-6206. doi: 10.1038/onc.2008.297.

Luo, L., Tam, J., Maysinger, D., Eisenberg, A., 2002. Cellular internalization of poly(ethylene oxide)-b-poly( $\varepsilon$-caprolactone) diblock copolymer micelles. Bioconjugate Chemistry, 13(6), pp.1259-1265. doi: 10.1021/bc025524y

Macia, E., Ehrlich, M., Massol, R., Boucrot, E., Brunner, C., Kirchhausen,T., 2006. Dynasore, a Cell-Permeable Inhibitor of Dynamin. Developmental Cell, 10(6), pp.839-850. doi: 10.1016/j.devcel.2006.04.002

Maldonado-Codina, C., Read, M.L., Efron, N., Dobson, C.B., Morgan, P.B., 2013. Observation of solution-induced corneal staining with fluorescein, rose bengal and 
lissamine green. Contact Lens and Anterior Eye, 36(5), pp.267-270. doi: 10.1016/j.devcel.2006.04.002

McIlwain, D.R., Berger, T., Mak, T.W., 2013. Caspase functions in cell death and disease. Cold Spring Harbor Perspectives in Biology, 5(4), pp.a008656-a008656. doi: 10.1101/cshperspect.a008656

McMonnies, C.W., 2007. Incomplete blinking: Exposure keratopathy, lid wiper epitheliopathy, dry eye, refractive surgery, and dry contact lenses. Contact Lens and Anterior Eye, 30(1), pp.37-51. doi: 10.1016/j.clae.2006.12.002

Mills, J.C., Stone, N.L., Erhardt, J., Pittman, R.N., 1998. Apoptotic membrane blebbing is regulated by myosin light chain phosphorylation. The Journal of Cell Biology, 140(3), pp.627-636. doi: 10.1083/jcb.140.3.627

Mokhtarzadeh, M., Casey, R., Glasgow, B.J., 2011. Fluorescein Punctate Staining Traced to Superficial Corneal Epithelial Cells by Impression Cytology and Confocal Microscopy. Investigative Ophthalmology \& Visual Science, 52(5), pp.2127-2135. doi: 10.1167/iovs.10-6489

Morgan, P.B., Maldonado-Codina, C., 2009. Corneal staining: do we really understand what we are seeing? Contact lens and Anterior Eye, 32(2), pp.48-54. doi: 10.1016/j.clae.2008.09.004 
Rey-Rico, A., Silva, M., Couceiro, J., Concheiro, A., Alvarez-Lorenzo, C., 2011. Osteogenic efficiency of in situ gelling poloxamine systems with and without bone morphogenetic protein-2. European Cells and Materials, 21, pp.317-340. doi: 10.22203/eCM.v021a24

Sandez-Macho, I., Casas, M, Lage, E.V., Rial-Hermida, I., Concheiro, A., AlvarezLorenzo, C., 2015. Interaction of poloxamine block copolymers with lipid membranes: Role of copolymer structure and membrane cholesterol content. Colloids and Surfaces B: Biointerfaces, 133, pp.270-277. doi: 10.1016/j.colsurfb.2015.06.019

Savic, R., Luo, L., Eisenberg, A., Maysinger, D., 2003. Micellar nanocontainers distribute to defined cytoplasmic organelles. Science, 300(5619), pp.615-618. doi: 10.1126/science. 1078192

Scarlett, A., Gee, P., 2007. Corneal abrasion and alkali burn secondary to automobile air bag inflation. Emergency Medicine Journal, 24(10), pp.733-734. doi: 10.1136/emj.2006.045658

Smally, J.A., Binzer, A., Dolin, S., Viano, D., 1992. Alkaline Chemical Keratitis: Eye Injury From Airbags. Annals of Emergency Medicine, 21(11), pp.1400-1402. doi: 10.1016/S0196-0644(05)81911-0 
Tabery, H.M., 2003a. Corneal surface changes in keratoconjunctivitis sicca. Part I: the surface proper. A non-contact photomicrographic in vivo study in the human cornea. Eye, 17(4), pp.482-487. doi: 10.1038/sj.eye.6700401

Tabery, H.M., 2003b. Corneal surface changes in keratoconjunctivitis sicca. Part II: the mucus component. A non-contact photomicrographic in vivo study in the human cornea. Eye, 17(4), pp.488-491.doi: 10.1038/sj.eye.6700400

Tabery, H.M., 1992. Dual appearance of fluorescein staining in vivo of diseased human corneal epithelium. A non-contact photomicrographic study. The British Journal of Ophthalmology, 76(1), pp.43-44. doi: 10.1136/bjo.76.1.43

Tchao, R., McCanna, D.J, Miller, M.J., 2002. Comparison of Contact Lens Multipurpose Solutions by In Vitro Sodium Fluorescein Permeability Assay. Eye \& Contact Lens-Science and Clinical Practice, 28(3), p.151. doi: 10.1097/01.ICL.0000019763.45071.F0

Tilia, D., Zhu, H., Thomas, V., Willcox, M., Holden, B., Lazon de la Jara, P., 2012. Abstract: Associations between solution induced corneal staining, corneal infiltrative events, and Gram-negative bacteria case contamination. Contact Lens and Anterior Eye, 35, pp.e25-e26.

Tsai, CC., Lin, CH., Wanf, TL., Chou, AC., Chou, MY., Lee, CH., Peng, IW., Liao, JH., Chen, YT., Pan, CY., 2009. Dynasore inhibits rapid endocytosis in bovine 
chromaffin cells. American Journal of Physiology - Cell Physiology, 297(2), pp.C397-C406. 10.1152/ajpcell.00562.2008.

Ward, K.W., 2008. Superficial punctate fluorescein staining of the ocular surface.

Optometry and Vision Science, 85(1), pp.8-16. doi: 10.1097/OPX.0b013e31815ed756

Wilson, G., Ren, H., Laurent, J., 1995. Corneal epithelial fluorescein staining. Journal of the American Optometric Association, 66(7), pp.435-441.

Wilson, S.A., Last, A., 2004. Management of Corneal Abrasions. American Family Physician, 70, pp.123-128.

Wipperman, J.L. \& Dorsch, J.N., 2013. Evaluation and Management of Corneal Abrasions, American Family Physician, 87(2), pp.114-120.

Wright, A., Mowrey-McKee, M., 2005. Comparative cytotoxicity potential of soft contact lens care products. Cutaneous and Ocular Toxicology, 24(1), pp.53-64. doi: 10.1081/CUS-200046191

Yamada, H., Li, SA., Masuoka, Y., Isoda, M., Watanabe, M., Nasu, Y., Kumon, H., Asai, A., Takei, K., 2009. Dynasore, a dynamin inhibitor, suppresses lamellipodia formation and cancer cell invasion by destabilizing actin filaments. Biochemical and Biophysical Research Communications, 390(4), pp.1142-1148. doi: 10.1016/j.bbrc.2009.10.105 
Ziegler, U., Groscurth, P., 2004. Morphological Features of Cell Death. Physiology, 19(3), pp.124-128 doi: 10.1152/nips.01519.2004 
Figure 1: Fluorescein and propidium iodide staining after MPS treatment. L929 cells were treated with MPS, and then stained with $0.01 \% \mathrm{w} / \mathrm{v}$ fluorescein or propidium iodide. (A) Representative fluorescence microscopy images show differential intensities of fluroescein staining with MPS treatment in L929 cells. (B) Quantification of fluorescence intensity in MPS-treated L929 cells or (C) MPStreated HC cells by HCA using the Cellomics Array Scan VTI HCS Reader. Fluorescence microscopy images were taken using 20x magnification and scale bars represent $100 \mu \mathrm{m}$. Fluorescence intensity is presented as its median value, and error bars represent the associated $95 \% \mathrm{CI}$ limits. Typical data is shown. 


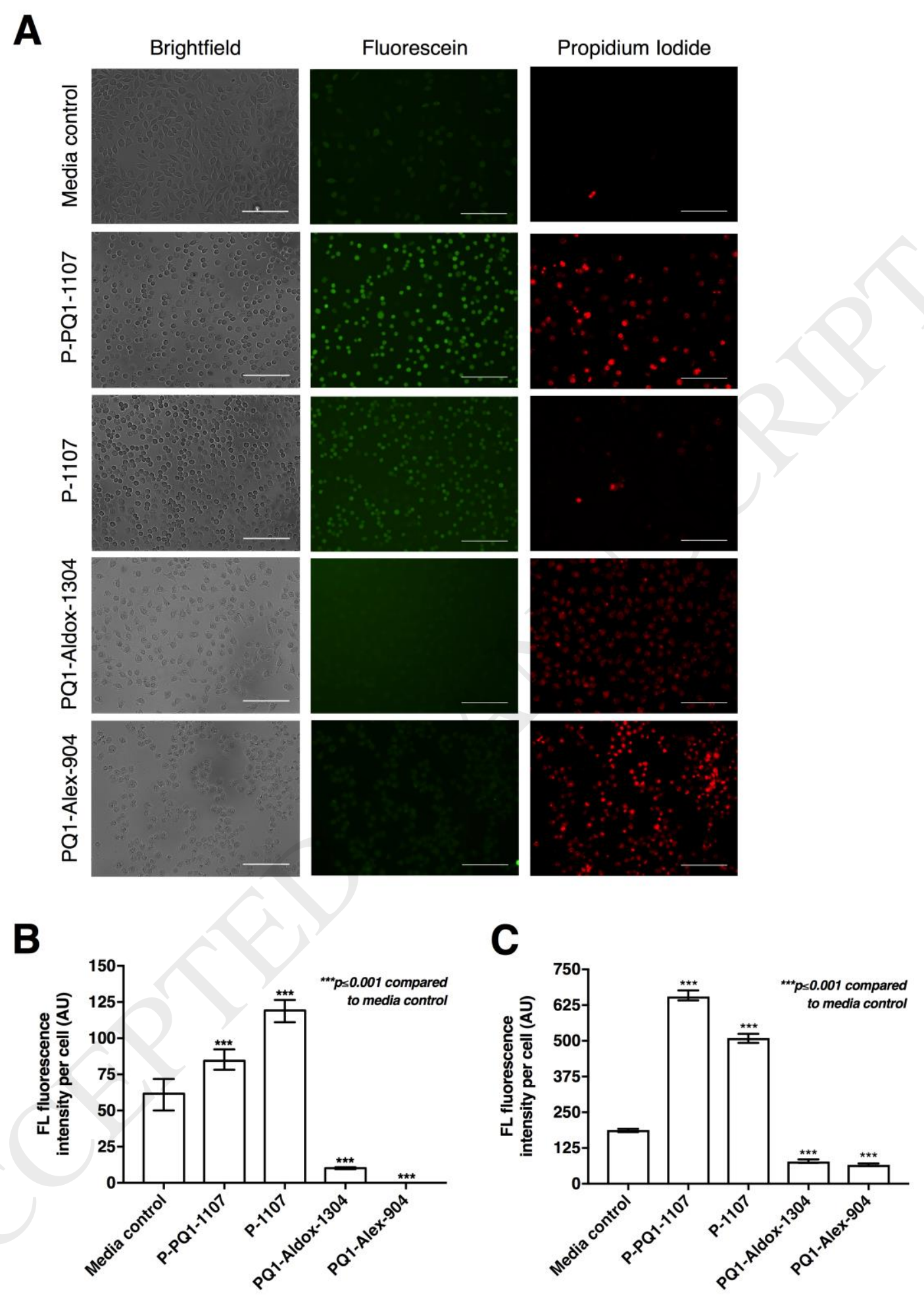


Figure 2: Effect of MPS-treatment on cell viability. (A) L929 cells stained with fluorescein and propidium iodide after treatment with $0.01 \%(\mathrm{w} / \mathrm{v}) \mathrm{BKC}$ for $10 \mathrm{~min}$. (B) Metabolic activity in L929 cells assessed using an MTT assay after exposure to MPS with or without $0.01 \% \mathrm{w} / \mathrm{v}$ fluorescein or $(\mathbf{C})$ metabolic activity assessed using an MTT assay in $\mathrm{HC}$ cells. Fluorescence microscopy images were taken using 10x magnification and scale bars represent $100 \mu \mathrm{m}$. All metabolic activity data is presented as a percentage relative to media control and error bars represent $95 \%$ CI limits. Data is representative of several experiments.

A

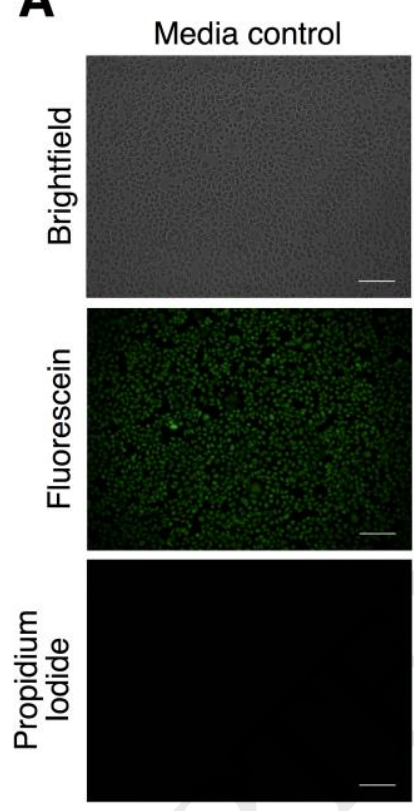

BKC
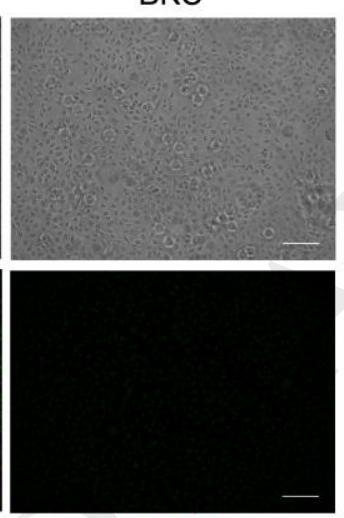

B

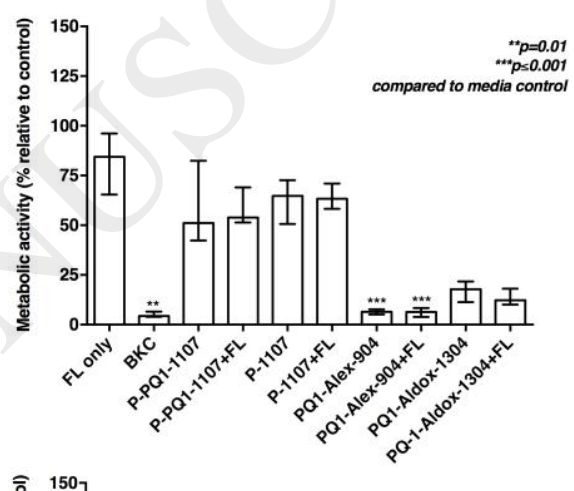

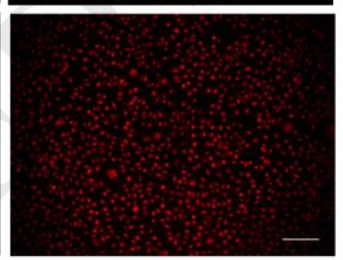

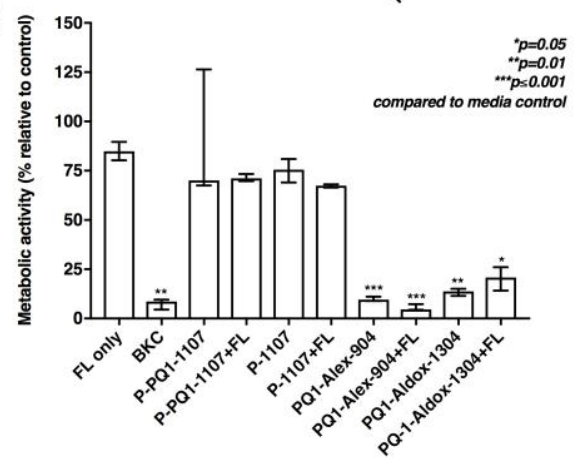


Figure 3: MPS treatment can cause membrane blebbing.

(A) Confocal microscopy images of L929 and HC cells after MPS treatment and exposure to $0.01 \% \mathrm{w} / \mathrm{v}$ fluorescein. 'Blebbing' was consistently observed after P-PQ11107 treatment, though not P-1107 treatment, for both cell types. Confocal images were taken using 40x magnification, and scale bars represent $10 \mu \mathrm{m}$ and $50 \mu \mathrm{m}$ for L929 and HC cells respectively. (B) L929 cells treated with MPS and fluorescein and immunostained for cleaved caspase-3. Fluorescent microscopy images were taken using 20x magnification and scale bars represent $100 \mu \mathrm{m}$. All images are representative of several fields of view.
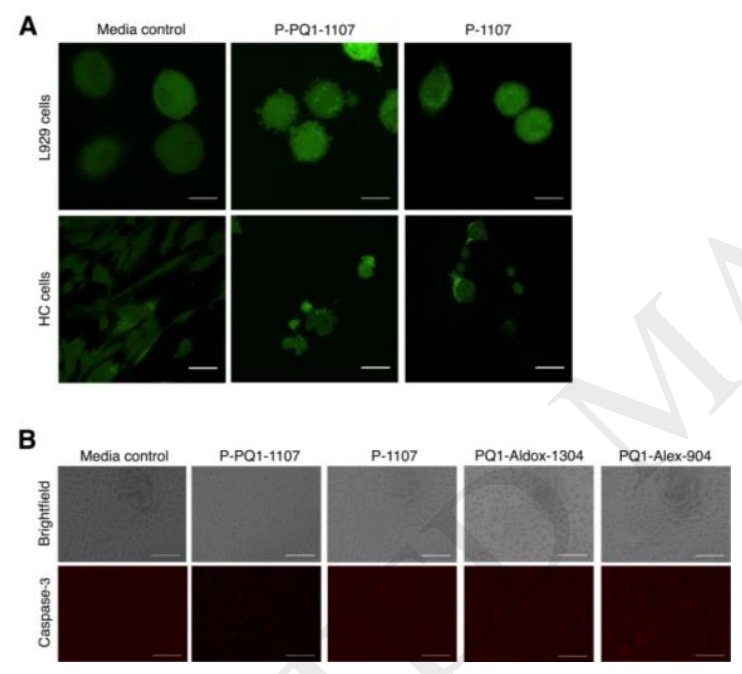
Figure 4: Dynamin inhibition reduces fluorescein uptake. (A) Effect of dynasore on the intensity of fluorescein uptake by L929 cells after treatment with MPS or (B) for $\mathrm{HC}$ cells. To confirm fluorescein uptake inhibition was not caused by a non-specific cytotoxic effect of dynamin-inhibition, the metabolic activity of L929 and HC cells respectively was measured after treatment with MPS, dynasore and fluorescein as above. No significant difference was seen between treatments in (C) L929 and (D) HC cells when compared to control; typical data shown. Metabolic activity is presented as a percentage relative to control and error bars represent the associated 95\% CI limits.

A

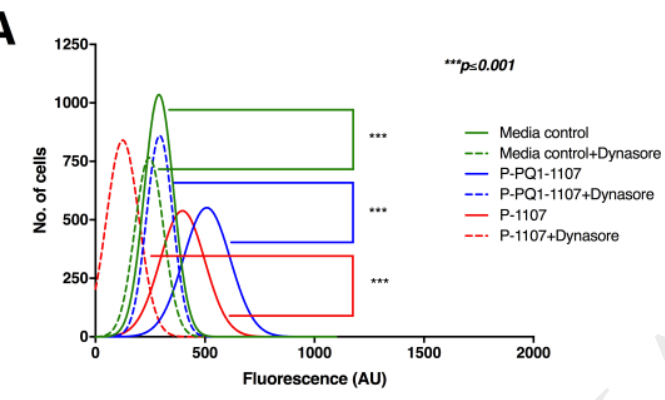

C

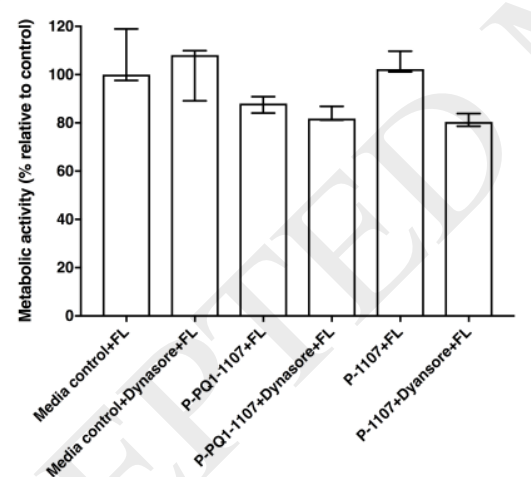

B

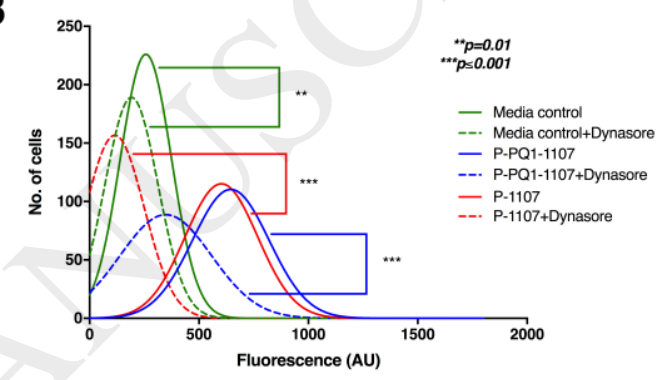

D

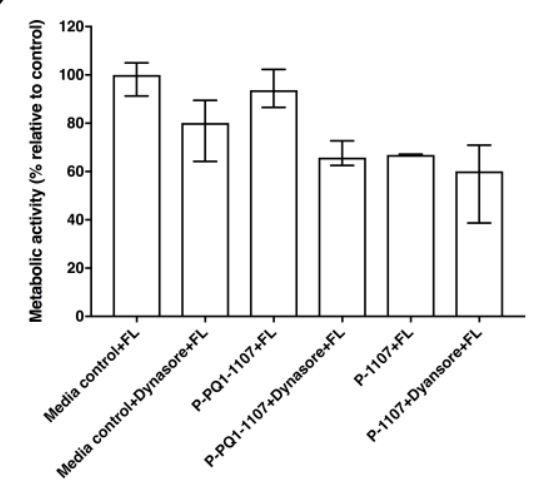


Figure 5: Role of MPS surfactants in increasing fluorescein uptake. (A) L929 or

(B) HC cells were treated with MPS or surfactants and exposed to fluorescein before data acquisition by HCA. Fluorescein fluorescence intensities are presented as median intensity values. (C) Effect of the surfactant Triton X-100 on fluorescein uptake by HC cells. We examined whether the increased fluorescein fluorescence after treatment with Tetronic 1107 may reflect increased metabolic activity. (D) and (E) show the metabolic activity of L929 cells ( $\mathrm{n}=4$ wells) and HC cells ( $\mathrm{n}=3$ wells) respectively, after MPS or surfactant treatments, or (F) after Triton X-100 treatment of $\mathrm{HC}$ cells ( $\mathrm{n}=4$ wells). Metabolic activities are presented as percentage relative to media control. All error bars represent the associated 95\% CI limits. Typical data shown.

A

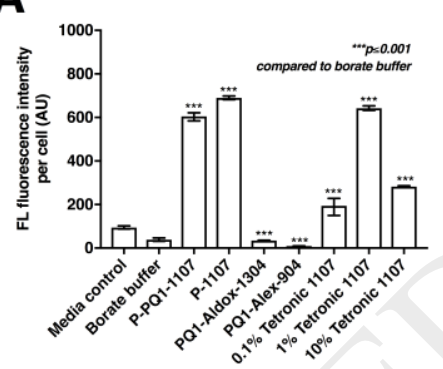

D

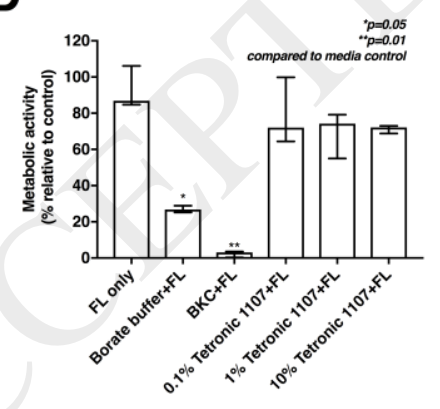

B

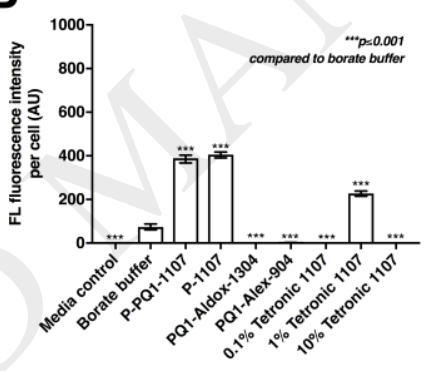

E

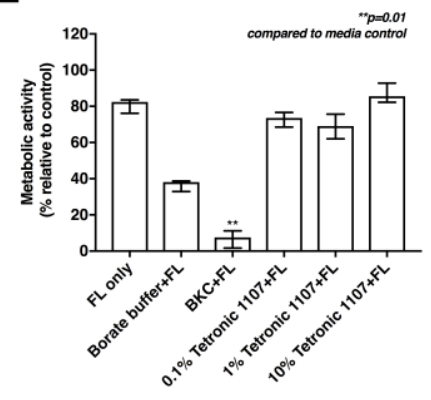

C

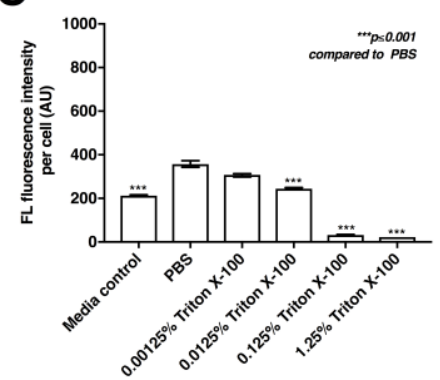

F

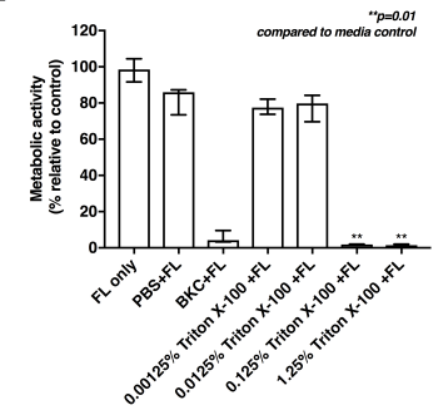


Table 1: MPS formulations. MPS are referred to by biocide and surfactant combinations. P, PQ1, Aldox, and Alex refer to the biocides PHMB, Polyquaternium-1, Aldox and Alexidine dihydrochloride respectively. 1107, 1304 and 904 refer to surfactants Tetronic 1107, Tetronic 1304 and Tetronic 904 respectively.

\begin{tabular}{|c|c|c|c|}
\hline MPS & Manufacturer & Biocide(s) & Surfactant \\
\hline $\begin{array}{l}\text { Biotrue } \\
\text { P-PQ1-1107 }\end{array}$ & Bausch+Lomb & $\begin{array}{l}\text { Polyquartenium-1 }(0.0001 \%) \\
\text { PHMB }(0.00013 \%)\end{array}$ & Tetronic ${ }^{\circledR} 1107$ (1.0\%) \\
\hline $\begin{array}{l}\text { ReNu Sensitive } \\
\text { P-1107 }\end{array}$ & Bausch+Lomb & PHMB (0.00005\%) & Tetronic® 1107 (1.0\%) \\
\hline $\begin{array}{l}\text { Opti-free Replenish } \\
\text { PQ1-Aldox-1304 }\end{array}$ & Alcon & $\begin{array}{l}\text { Polyquaternium-1 }(0.001 \%) \text {, } \\
\text { ALDOX }(0.0005 \%)\end{array}$ & Tetronic ${ }^{\circledR} 1304(0.05 \%)$ \\
\hline $\begin{array}{l}\text { Complete Revitalens } \\
\text { PQ1-Alex-904 }\end{array}$ & AMO & $\begin{array}{l}\text { Polyquaternium-1 }(0.0003 \%) \text {, } \\
\text { Alexidine dihydrochloride } \\
(0.00016 \%)\end{array}$ & Tetronic $₫ 904(0.1 \%)$ \\
\hline
\end{tabular}


Table 2: Composition of Tetronic $®$ surfactants in the MPS formulations used in the study. The number of ethylene oxide (EO) and propylene oxide (PO) units per block is shown (Alvarez-Lorenzo et al. 2010).

\begin{tabular}{ccccc}
\hline Tetronic & $\begin{array}{c}\text { Mw } \\
(\mathbf{D a})\end{array}$ & $\begin{array}{c}\text { EO units } \\
\text { per block }\end{array}$ & $\begin{array}{c}\text { PO units } \\
\text { per block }\end{array}$ & $\begin{array}{c}\text { Hydrophilic-Lipophilic } \\
\text { balance (HLB) }\end{array}$ \\
\hline 904 & 6700 & 15 & 17 & $12-18$ \\
1107 & 15000 & 60 & 20 & $18-23$ \\
1304 & 10500 & 21.4 & 27.1 & $12-18$ \\
\hline
\end{tabular}

